\title{
Sydsudan: Vanskelige forhandlinger om fred
}

\section{Mads Qvortrup}

Krigen i Dafur har overskygget konflikten i Sydsudan hvor forhandlingerne om en endelig fredsløsning går trægt. Mads Qvortrup er med i den forhandlingsdelegation der forhandler om fred

Der ligger en tung blågrå dyne af dis over Juba i det sydlige Sudan. Røgen fra bålene uden for hytterne blander sig med dunsten af kvægekskrementer og lyden af firhjulstrækkere.

Gaderne - eller retter de støvede grusveje - er tomme. Der er udgangsforbud. Den tidligere oprørshær The Sudan Peoples' Liberation Army (SPLA) som nu styrer denne del af landet, gennemfører en razzia. Der er blevet fundet våben, og aftenen inden har der været skyderier uden for det alt andet end Grand Hotel.

"Jesus Almighty, hvorfor lige i dag", siger den amerikanske sikkerhedsmand, der har ansvaret for den lille delegation af fredsmæglere der, på denne dag - igen - er rejst til Sydsudans 'hovedstad' for at lede forhandlingerne mellem den (overvejende) muslimske regering $\mathrm{i}$
Khartoum og den (mestendels) kristne regering i Sydsudan.

Efter planen skal der i 2011 afholdes en folkeafstemning om hvorvidt Sydsudan skal løsrive sig fra resten af Sudan, men forhandlingerne omfolkeafstemningen og processen i øvrigt går ikke godt.

\section{Et kludetæppe af konflikter}

Sudan er et miskmask af overlappende konflikter. Det har det altid været.

"Ve dig, du land, hvor græshopperne svirrer, landet bag Nubiens strømme”. Sådan står der i Esajas Bog (18.1). Allerede dengang i Gammel Testamentlig tid var der konflikter mellem de sorte stammefolk og deres nordlige naboer.

Siden Sudans selvstændighed i 1956 har stammer i syd (der er for- 
trinsvis kristne) kæmpet mod regeringen i nord (der er muslimsk). For at gøre kludetæppet endnu mere kompliceret har regeringen $\mathrm{i}$ Khartoum også - ofte via stedfortrædere - været i krig med muslimske stammer i Dafur i den vestlige del af landet.

Det er især den sidste konflikt der har påkaldt sig verdenssamfundets opmærksomhed. Gennem den såkaldte Janjaweed milits har regeringen i Khartoum fordrevet områdets ikke-arabiske (men muslimske) befolkningsgrupper. 250.000 har mistet livet siger FN og den Afrikanske Union.

Men det er den mere eller mindre konstante krig mellem Khartoum og forskellige stammer i syd der har varet længst. Denne krig blussede for alvor op, da regimet i nord i 1983 indførte Sharia i hele Sudan.

Men i 2005 indgik præsident Umar Hasan Ahmad al-Bashir en fredsaftale med oprørslederen John Garang de Mabior. Ifølge den såkaldte Comprehensive Peace Agreement (CPA) blev der indført en magtdeling, med SPLMs leder som vice-præsident, udvidet uafhængighed af Sydsudan, ophævelse af Sharia i den sydlige del af landet og mulighed for at stemme om selvstændighed efter en seksårig overgangsperiode. Det er denne overgangsperiode der nu næsten er slut.

I mellemtiden er der sket en del. John Gerang døde i en helikopter ulykke kort efter fredsaftalen var blevet underskrevet. I modsætning til sin forgænger har Garangs efterfølger Salva Kiir Mayardit ikke ambitioner om at lede hele Sudan. SPLM ønsker nu selvstændighed - og håber på, at de kan drage nytte af de olieforekomster der findes i den nordlige del af Sydsudan.

NCP ønsker ikke en opsplitning af landet. Konflikten i Dafur er blevet dysset ned. Det internationale samfund accepterer at der er sket forbedringer. Men trods dette er præsident al-Bashir blevet indstæunet for den Internationale Strafdomstol (ICC) i Haag.

Men fokus er fortsat på Dafur. $\mathrm{Og}$ under dække af dette har NCP, angiveligt, optrappet konflikten i Sydsudan. UNMIS - de Forenede Nationer Sudan - anslår, at der dræbes 2000 mennesker om måneden i Sydsudan. Mestendels af stedfortrædere der - det siges i hvert fald støttes af henholdsvis SPLM/A og NCP. Samtidigt er SPLM begyndt at samarbejde med de politiske grupper i Dafur.

\section{Ved forhandlingsbordet}

I slutningen af september samledes alle oppositionsgrupperne i Juba. NCP var fortørnet.

Det er i skyggen af dette, at den amerikanske general Scott Gration er blevet udsendt for at finde en fredsløsning. Målet er en fredelig afholdelse af folkeafstemningen i 2011 og en mindelig løsning på kon- 
flikten overalt i Sudan. Det er vanskeligt!

Det er for at deltage i disse forhandlinger, at jeg denne tidlige novembermorgen venter på at udgangsforbudet skal blive hævet. For fire måneder siden var jeg på ferie. Mine børn hujede, mens de kørte rundt på rutsjebanen i Thorpe Park. Telefonen ringede. Det var udenrigsministeriet.

"Det er folkeafstemningen i Sudan. Amerikanerne vil gerne have dig med. Du rejser på fredag". Og nu er jeg her.

Udenfor kan man se en større SPLA (Sudan People's Liberation Army red.) enhed marchere ned ad den støvede hovedgade. Militær anstand er der ikke megen af. De fleste har kondisko på, men andre har bare fødder og atter andre sandaler. Nogle har T-shirts, men de bærer alle på AK-47 rifler. Det russiske stormgevær der ofte går under navnet Kalasjnikov. Det er ikke nogen ideal start på forhandlingerne.

Stemningen er hård og uforsonlig. Det siger sig selv, at jeg ikke i detaljer kan citere fra forhandlingerne, endsige give navne på alle deltagerne. Men National Congress Party (NCP) hovedforhandleren Ghazi Salahuddin Atabani og hans modpart SPLM's Malik Agar sidder tavst over for hinanden, mens deres adjudanter med slet skjulte henvisninger truer modparten.

De er forskellige. Ghazi er lille, taler med spag stemme og er i alle må- der sindbilledet på den arabiske intellektuelle. Jovist, også han har medvirket til beslutninger der har kostet tusinder af menneskeliv - og også han har været i krig. Men det er han ikke ene om. "Hvis Gud straffede synderne, ville ingen være $\mathrm{i}$ live", skriver Koranen (16.56).

Hans modpart er Malik Agar. Han er høvding fra Nuer stammen. I Esajas Bog i Det Gamle Testamente beskrives Nuerne som "det granvoksne, glinsende folk, som frygtes vidt omkring". De fleste Nuer - også kvinderne - er over $186 \mathrm{~cm}$.

Malik - alle bruger fornavne i denne del af verden - er ingen undtagelse. Han er over $190 \mathrm{~cm}$. Hans overarme er så tykke som telefonpæle og hans stemme så dyb og mørk som hans kulsorte hud. Som ung førte han stammen igennem ørkenen for at undgå krigen. De vandrede 1000 kilometer. Og måske er det af denne grund, at den store kulsorte mand minder om Moses.

Der er en udskreven logik, en særegen koreografi om man vil, i fredsforhandlinger. Parterne lader de unge hedsporer udstikke positioner, prøver modparten af, og træder til side, når man begynder at nærme sig beslutninger. Denne morgen handler det om, hvorvidt der skal være et simpelt flertal ved folkeafstemningen.

NCP mener, at der skal et kvalificeret flertal til. " 75 procent skal stemme for selvstændighed. Ellers kan vi ikke acceptere det". Det bli- 
ver - selvsagt - afvist af SPLM, der på deres side kræver, at de alene skal tælle stemmerne.

Positionen er fastlåst. Og meget tyder på, at hele forhandlingen er en taktisk manøvre for at vinde tid. For mens forhandlingerne foregår, kommer der hele tiden efterretninger om, at 'banditter' har dræbt kvægdrivere, angrebet landsbyer og voldtaget kvinder.

Begge parter beklager det. Tager afstand fra det, og beskylder modparten for at stå bag.

\section{Olie}

Det handler ikke bare om politik. Sydsudan er indelukket og har ikke adgang til havet. Det ludfattige land har olie. Men rørledningen går igennem det nordlige Sudan. Hvis Sydsudan bliver selvstændigt er det nødvendigt at få olien ud. Og det er ikke realistisk at bygge en ny rørledning gennem fx Uganda eller Etiopien. En rørledning koster mere end en firesporet motorvej.

Men Khartoum vil have betaling for at lade Sydsudan bruge rørledningen. Det er en fastlåst situation. Bliver Sydsudan selvstændigt, vil Khartoum kræve 60 procent af olieindtægterne for at lade Juba-regeringen bruge rørledningen. Løsrivelse eller ej. Begge har en interesse $i$ at finde en løsning. Begge kan tjene penge på olien. Især hvis de sælger den til kineserne, der køber 60 procent af Sudans olie.
Regeringen i Khartoum har en interesse $i$ at vise velvilje og $i$ at få ophævet arrestordren på General AlBashir - og en interesse i at tjene penge. De har ikke selv olie. En mindelig løsning er deres eneste mulighed.

Men politik er ikke logik, endsige en eksakt videnskab. Den overordnede optik - som de bliver opfattet af en vestlig fredsmægler - er ikke nødvendigvis den rigtige.

For begge parter er der hensynet til yderliggående kræfter i deres respektive baglande. Og de interesserer sig ikke bare for olie eller international politik. Mange i SPLM er mistænkelige over for Khartoum. Og mange i Khartoum mener - primært af religiøse årsager - at man ikke kan tillade, at der opstår et kristent land i et land der, officielt er styret efter Sharia-principper. Men der er også historiske årsager. Gamle konflikter og tusind års fjendskab kan ikke løses i et konferencecenter med aircondition.

\section{Sejren er vor}

"Sejren er vor" bliver der sagt på arabisk. Det sprog taler jeg ikke. "Det er det nationale motto", hvisker min kollega til mig. Han har været her i mange år, og kender sproget, kulturen og de mange forviklinger.

Det er ikke indlysende hvorfor den underordnede forhandler er så tilsyneladende triumferende, da han 
- i en pause af forhandlingerne ringer til hovedkvarteret i Khartoum.

Jeg overhører hans samtale på balkonen uden for Home and Away, hvor fredsforhandlingerne foregår. Forhandlingerne fører ingen vegne. Efter to dage er parterne endnu længere fra hinanden. Og SPLM har eksplicit truet med at erklære sig uafhængigt 'uanset hvad'. Vi ved vi skal mødes to uger senere. Så måske er der håb. Det er som om, at det er denne hårdknude, der begejstrer den ungdommeligt udseende arabiske forhandler.
Da jeg senere om aftenen indtager min aftensmad, fortæller han, at han har studeret på militærakademiet i Tyrkiet. Han har læst den tyske teoretiker Carl von Clausewitz. "Du ved det er ham der sagde, at 'krigen er politikkens fortsættelse med andre midler'".

Måske har han lært lidt for meget af den gamle prøjsiske krigsherre.

Mads Qvortrup, D.Phil er rådgiver for det amerikanske udenrigsministerium og deltager som ekspert i fredsforhandlingerne $i$ Sudan. 